\title{
Social network assessment in community-dwelling older persons: results from a study of three European populations
}

\author{
Eva Blozik ${ }^{1,2,3}$, Jan T. Wagner ${ }^{1,2}$, Gerhard Gillmann ${ }^{2}$, Steve Iliffe ${ }^{3}$, Wolfgang von Renteln-Kruse ${ }^{4}$, \\ James Lubben ${ }^{5}$, John C. Beck ${ }^{6,7}$, Andreas E. Stuck ${ }^{1,8}$ and Kerri M. Clough-Gorr ${ }^{1,2,8,9}$ \\ ${ }^{1}$ Department of Geriatrics, Inselspital University of Bern Hospital, Bern, Switzerland, ${ }^{2}$ Institute of Social and \\ Preventive Medicine, University of Bern, Bern, Switzerland, ${ }^{3}$ Department of Primary Care and Population \\ Sciences, University College London, Hampstead Campus, London, United Kingdom, ${ }^{4}$ Albertinen-Haus \\ Geriatrics Centre, University of Hamburg, Hamburg, Germany, ${ }^{5}$ School of Social Work, Boston College, \\ Chestnut Hill, MA, USA, ${ }^{6}$ School of Medicine, University of California, Los Angeles, Los Angeles, CA, \\ USA, ${ }^{7}$ Langley Research Institute, Pacific Palisades, CA, USA, ${ }^{8}$ University Department of Geriatrics, Spital \\ Netz Bern Ziegler, Bern Switzerland, ${ }^{9}$ Geriatrics Section, Boston University Medical Center, Boston, MA, USA
}

ABSTRACT. Background and aims: In clinical practice, the status of living alone is often used as the only measure describing an older person's social network. We evaluated whether additional use of a brief social network measure provides relevant additional information in relation to social support and engagement. Methods: Cross-sectional survey of 6982 community-dwelling adults 65 years or older living in London, UK; Hamburg, Germany; and Solothurn, Switzerland. Data were collected using the self-administered multidimensional Health Risk Appraisal Questionnaire. Multivariate models were used to analyse adjusted correlations between the two measures of social network (living alone status, risk for social isolation with marginal family and friend network subscales) and potential consequences of inadequate social network (marginal emotional or instrumental support, lack of social engagement). Results: Living alone status was more strongly associated with marginal instrumental support [OR $=7.6(95 \%$ CI 6.3, 9.1)] than with marginal emotional support [OR $=4.2$ (95\% CI 3.4, 5.1)], and showed no statistically significant association with lack of social engagement $[O R=0.9(95 \% \mathrm{CI} 0.8,1.0)]$. Risk of social isolation was more strongly related to marginal emotional support $[O R=6.6(95 \%$ CI 5.4, 8.0)] than to marginal instrumental support [OR=3.3 (95\% CI 2.8, 4.0)], and was moderately related to lack of social engagement $[O R=2.9$ (95\% CI 2.5, 3.4]. Marginal family and friend network subscales showed consistent and unique associations with social support and social engagement. Conclusion: Findings suggest that living alone status and a brief measure of social network identifies distinctive at-risk groups and potential pathways for intervention. Geriatric assessment programs including both social network measures may provide useful information about potentially modifiable social network risks in older persons.

(Aging Clin Exp Res 2009; 21: 150-157)

${ }^{\circ}$ 2009, Editrice Kurtis

\section{INTRODUCTION}

The social network provides many benefits that have been associated with the overall health and well-being of older adults (1). An individual's social network provides a reservoir for social engagement, and buffers the impact of major life events by providing emotional and instrumental social support in times of crisis. Although the causal relationship between social network and health is not completely understood, it is hypothesized to function through multiple pathways that include social support and social engagement $(2,3)$. Thus, an adequate social network, closely related to social-structural characteristics that vary from culture to culture, is conceptualized to precede the existence of social support and engagement, intermediaries of health and well-being $(2,4)$. The reported health benefits associated with a social network are: less risk of early death, better physical and mental health, less risk of

Key words: Geriatric assessment, older adults, social engagement, social isolation, social network, social network assessment, social support. Correspondence: Andreas E. Stuck, MD, University Department of Geriatrics, Spital Netz Bern Ziegler, Morillonstrasse 75-91, CH-3001 Bern, Switzerland.

E-mail: andreas.stuck@spitalnetzbern.ch

Received March 4, 2008; accepted in revised form July 14, 2008. 
disability or decline in activities of daily living, and better chance of recovering ability to perform activities of daily living (5-8). For those reasons, lack of a social network or risk of social isolation is a potentially modifiable risk factor for functional status decline and other adverse health outcomes in older adults (1, 9-13).

Despite this, multidimensional geriatric health-risk assessment usually only includes single-item proxy measures, such as living alone status $(13,14)$. An important reason for limited assessment of the social network is the lack of brief social network screening instruments that can be easily incorporated into multidimensional geriatric health-risk assessment. This limitation has been recently addressed by the development of the six-item Lubben Social Network Scale (LSNS-6) which has shown good validity and reliability in community-dwelling older adults $(4,15,16)$.

In the context of a multidimensional geriatric health-risk assessment program, we investigated a social network assessment that included two social network measures (living alone status and risk of social isolation using the LSNS-6 with family and friend subscales) in relation to social support and engagement across three populations of European community-dwelling older adults. Because the social network is based on social-structural and personal characteristics, which may differ considerably, our populations also served as opportunities to evaluate the sensitivity of the brief social network measure. Our analyses were based on the conceptual framework proposed by Berkman et al. (Fig. 1) (2, 4). Our a priori hypothesis was that differences in associations would exist between the two measures of social network, suggesting that a differentiated social network assessment with more than a single-item measure adds relevant and unique information to multidimensional geriatric health-risk assessment.

\section{METHODS}

\section{Study population}

This is a secondary analysis of baseline data from the PRO-AGE trial (PRevention in Older People - Assessment in GEneralists' practices), a multicenter study of a health-risk appraisal system among community-dwelling older adults living in London, UK; Hamburg, Germany; and Solothurn, Switzerland, conducted between 2001 and 2003. In London, the study sample included populations living mainly in the outer urban areas. In Hamburg, persons were recruited from both urban and suburban neighborhoods. Solothurn is mainly rural, and most individuals live in small villages or towns. The study was approved by local research ethics committees. A detailed description of the PRO-AGE study design is reported elsewhere $(17,18)$.

For recruitment of participants, 80 primary care practices in the selected project areas generated lists of all registered patients aged 65 years and older. Out of 21,391 persons on these lists, 11,750 persons were excluded, based on physician practice records according to a priori criteria (dependent in basic activities of daily living [ADL], cognitive impairment, terminal disease, did not speak regional language). Of the remaining 9641 persons who were enrolled in the study and received the Health Risk Appraisal for Older Persons (HRA-O) questionnaire, 1560 did

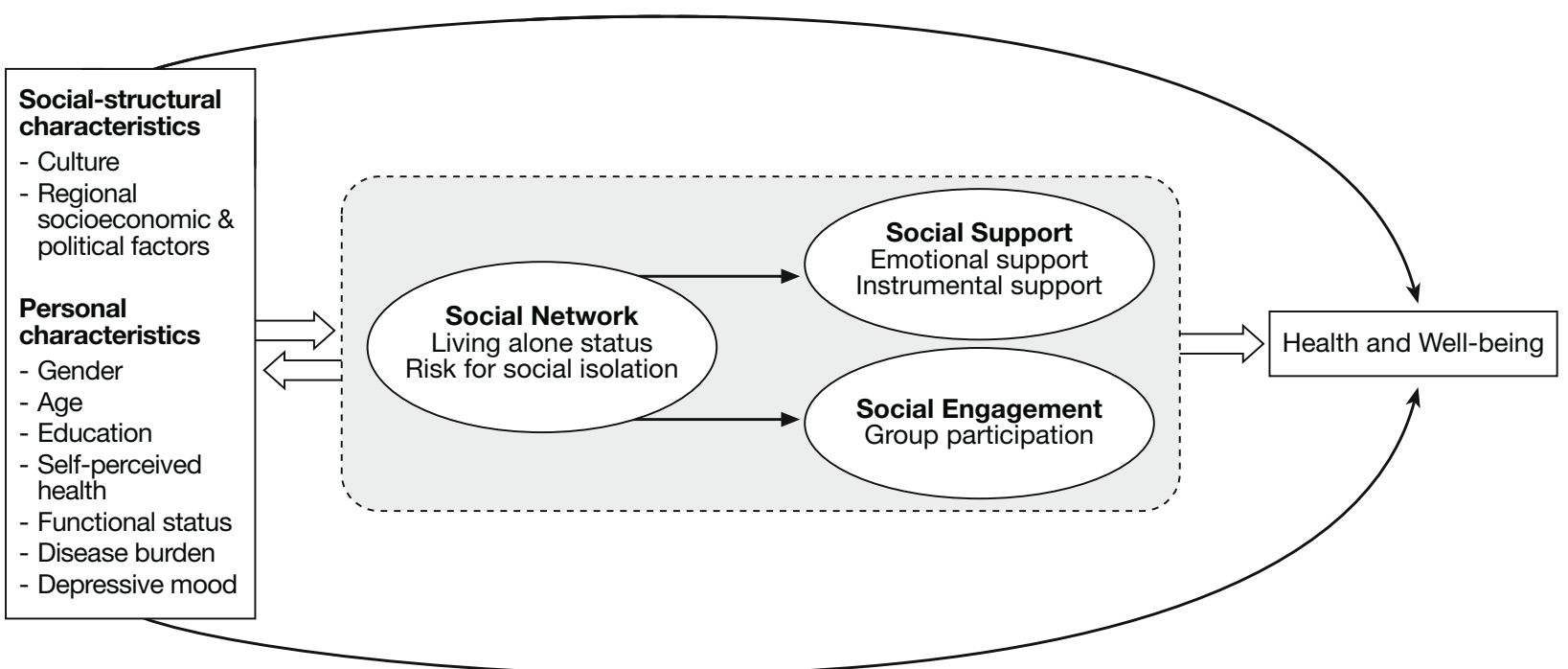

Based on conceptual framework by Berkman LF, Glass T, Brissette I, Seeman TE. From social integration to health: Durkheim in the new millennium. Soc Sci Med 2000;51:843-57.

Fig. 1 - Conceptual framework of associations between social network and other factors in older adults. 


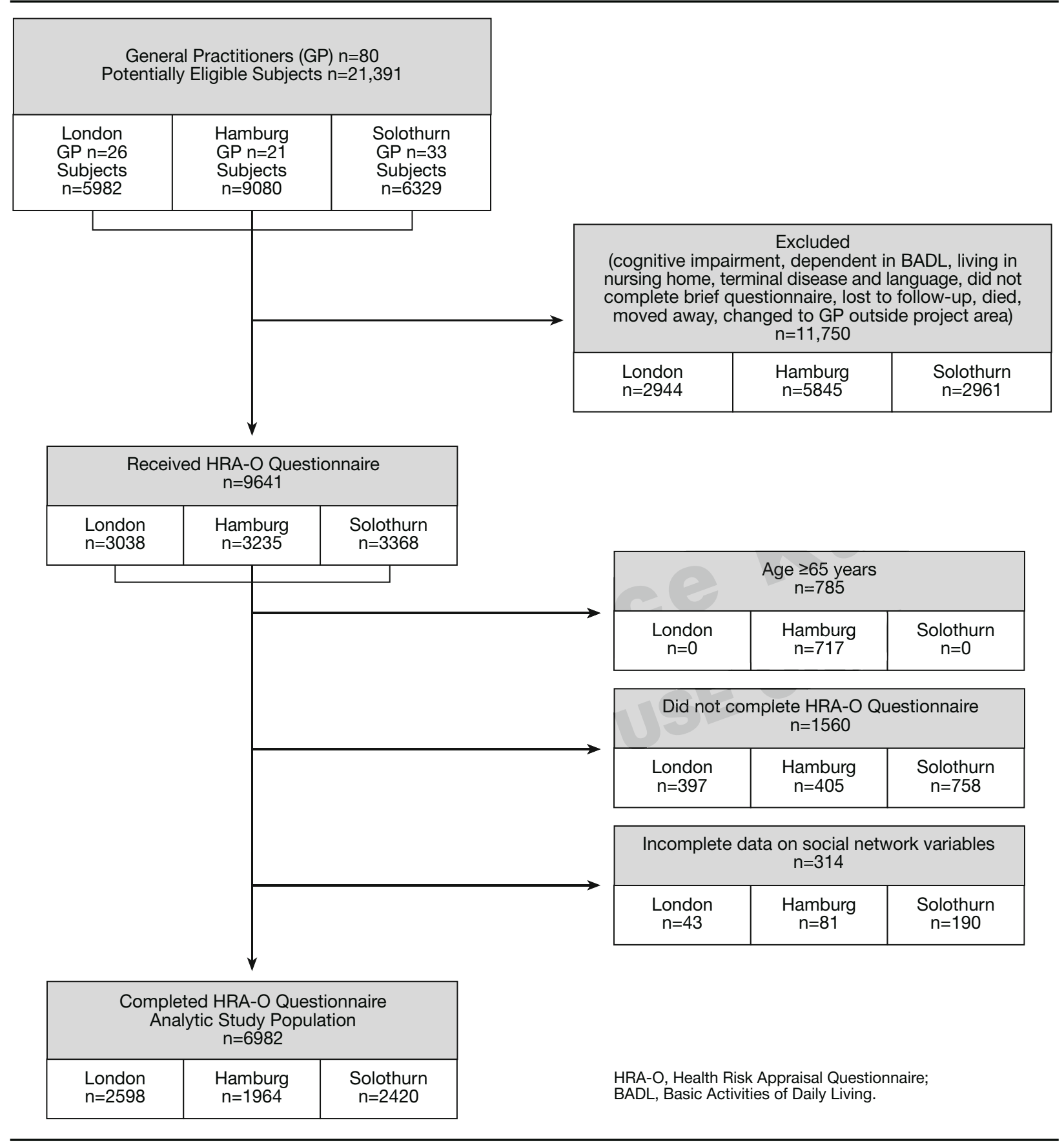

Fig. 2 - Study population flowchart.

not complete it, 314 had incomplete data on the social network variables, and 6982 (72\%) completed all sections (London=2589, Hamburg=1964, Solothurn=2420) and were included in the present analysis. Figure 2 shows the study population flowchart.

\section{Instruments for data collection}

Physician practice records and the HRA-O were used for data collection. Information on the development, reliability, and validity of the questionnaire has been previously published (19). 


\section{Measures of social network}

The HRA-O questionnaire contained two measures of social network. Living alone status was assessed by a single question: whether or not the respondent was currently living alone. Risk of social isolation was measured with the LSNS-6 score, calculated as an equally weighted sum of six items with scores ranging from zero to 30 (higher scores indicating better social network) $(1,15)$. The individual items of the LSNS-6 are listed in the Appendix. A person was defined, based on previous psychometric validation, as at risk of social isolation if the LSNS score was $<12(15,20)$. The scale can also be split into family and friend subscales (15). The family subscale is constructed from three items that ask about relatives similarly, the friends subscale was three items that ask about friends.

\section{Demographic and health-related characteristics}

Age and gender were obtained from physician practice records. We considered participants as having a low level of education if they reported no additional education after completion of the compulsory nine years of school.

Health-related characteristics were based on self-reported items from the HRA-O questionnaire and measured in four ways. Self-perceived health status was assessed using a single-item measure "All in all, would you say that your health is generally excellent, good, fair or poor?" Limitation in instrumental activities of daily living (IADL) was defined as difficulty and/or need for assistance in handling finances, taking medications, engaging in "handyman" work, doing housework, doing laundry, preparing meals, shopping, using the telephone and/or using transportation (21). Comorbidity was measured by the number of self-reported chronic medical conditions out of a list of 15 (22). Depressive mood was defined as a score $>66$ on the five-item Mental Health Inventory Screening Test $(23,24)$.

\section{Social support measures}

Emotional social support was measured using a threeitem version of the RAND Medical Outcome Study Social Support Survey (MOS-SSS) (25). The items included: "How often do you have someone who shows you love and affection if you need it?", "How often do you have someone to share your most private worries and fears with if you need it?" and "How often do you have someone to love and make you feel wanted?". Each item was scored on a scale ranging from zero to five, resulting in emotional social support scale values ranging from zero to 15 (15 indicating the highest level). Marginal emotional social support was defined as an emotional social support scale score $<6$ (1). Instrumental social support was assessed with a single-item yes/no question that asked whether or not the older adult had someone who would provide care for a few days if necessary (26).

\section{Measure of social engagement}

Social engagement was assessed dichotomously as group participation, by a single-item inquiring about monthly participation in groups such as hobby or recreational groups, community organizations including political or charity groups, and church or religious organizations $(27,28)$.

\section{Statistical analyses}

Summary statistics (univariate, proportion, and frequency) were used to describe the demographic and health-related characteristics of the study population. We examined bivariate relations using chi-square tests and Spearman correlations; first between the measures of social network, and then between social network measures and demographic and health-related characteristics, as well as measures of social support and social engagement. Multivariate logistic regression models were used to evaluate associations between social network measures and measures of social support and social engagement, adjusting for demographic and health-related characteristics. All variables were selected for inclusion in adjusted models based on their association with measures of social support and social engagement $(29,30)$. Last, we conducted analyses of non-response by comparing characteristics of respondents $(n=6982)$ with non-respondents $(n=1874)$ by means of Student's $t$-tests. All analyses were performed with STATA version 8.2 (STATA Corporation, College Station, TX, USA, 2003) and all $p$-values were two-sided.

\section{RESULTS}

Table 1 reports sample characteristics for the three sites. Except for emotional support, significant differences were noted among the sites. Approximately two-thirds of the individuals in the Hamburg sample were women, whereas older women constituted slightly more than half the sample in the other two sites. Sixty-three percent of participants from London, $25 \%$ from Hamburg and $40 \%$ from Solothurn had a low level of education, reflecting socio-economic differences in the selected project sites. Hamburg respondents were less likely to be living with a partner and also more apt to report deficiencies in various aspects of their social support networks than their counterparts in Solothurn and London. Because of a strong tradition of group activities in Switzerland, most of the participants from Solothurn reported participating in social groups, whereas this was less frequent in Hamburg and London. In sum, the three sites reflect important intergroup differences in social-structural and personal characteristics.

Each social network measure (individually analyzed) consistently demonstrated unique associations with social support and engagement measures across the three pop- 
Table 1 - Subject characteristics of three European populations of community-dwelling older adults (total sample, $n=6982$ ).

\begin{tabular}{|c|c|c|c|c|}
\hline & $\begin{array}{c}\text { London* } \\
\text { n (\%) } \\
(\mathbf{n}=\mathbf{2 5 9 8 )}\end{array}$ & $\begin{array}{c}\text { Hamburg* } \\
n(\%) \\
(n=1964)\end{array}$ & $\begin{array}{c}\text { Solothurn* } \\
\text { n (\%) } \\
(\mathbf{n = 2 4 2 0 )}\end{array}$ & $\begin{array}{c}\text { Between group } \\
\text { differences }^{\#}\end{array}$ \\
\hline \multicolumn{5}{|l|}{ Social network } \\
\hline Living alone & $842(33)$ & $785(41)$ & $705(30)$ & $\mathrm{L}<\mathrm{H}, \mathrm{L}>\mathrm{S}, \mathrm{H}>\mathrm{S}$ \\
\hline Risk for social isolation (LSNS-6 score <12) & $397(15)$ & $393(20)$ & $255(11)$ & $\mathrm{L}<\mathrm{H}, \mathrm{L}>\mathrm{S}, \mathrm{H}>\mathrm{S}$ \\
\hline Marginal family network (LSNS-6 family subscale score <6) & $379(15)$ & $350(18)$ & $176(7)$ & $\mathrm{L}<\mathrm{H}, \mathrm{L}>\mathrm{S}, \mathrm{H}>\mathrm{S}$ \\
\hline Marginal friend network (LSNS-6 friend subscale score <6) & $495(19)$ & $449(23)$ & $434(18)$ & $\mathrm{L}<\mathrm{H}, \mathrm{H}>\mathrm{S}$ \\
\hline \multicolumn{5}{|l|}{ Demographic and Health-related characteristics } \\
\hline Female gender & $1415(54)$ & $1233(63)$ & $1356(56)$ & $\mathrm{L}<\mathrm{H}, \mathrm{H}>\mathrm{S}$ \\
\hline Mean age $( \pm \mathrm{SD})$ & $74.5 \pm 6.2$ & $74.0 \pm 6.4$ & $73.9 \pm 5.9$ & $\mathrm{~L}>\mathrm{H}, \mathrm{L}>\mathrm{S}$ \\
\hline Age $\geq 75$ years & $1105(43)$ & $792(40)$ & $939(39)$ & $\mathrm{L}>\mathrm{S}$ \\
\hline Low level of education ( $\leq$ basic school) & $1618(63)$ & $456(25)$ & $986(43)$ & $\mathrm{L}>\mathrm{H}, \mathrm{L}>\mathrm{S}, \mathrm{H}<\mathrm{S}$ \\
\hline Fair/poor self-perceived health & $625(24)$ & $633(33)$ & 457 (19) & $\mathrm{L}<\mathrm{H}, \mathrm{L}>\mathrm{S}, \mathrm{H}>\mathrm{S}$ \\
\hline \multicolumn{5}{|l|}{ Functional status } \\
\hline Limitation in $\geq 2$ IADL & $452(18)$ & $539(28)$ & $514(22)$ & $\mathrm{L}<\mathrm{H}, \mathrm{L}<\mathrm{S}, \mathrm{H}>\mathrm{S}$ \\
\hline \multicolumn{5}{|l|}{ Disease burden } \\
\hline $\begin{array}{l}\text { Mean number of chronic conditions }( \pm \mathrm{SD}) \\
\geq 3 \text { chronic medical conditions }\end{array}$ & $\begin{array}{l}2.0 \pm 1.5 \\
851(34)\end{array}$ & $\begin{array}{c}3.0 \pm 1.8 \\
1078(59)\end{array}$ & $\begin{array}{l}2.3 \pm 1.6 \\
932(41)\end{array}$ & $\begin{array}{l}\mathrm{L}<\mathrm{H}, \mathrm{L}<\mathrm{S}, \mathrm{H}>\mathrm{S} \\
\mathrm{L}<\mathrm{H}, \mathrm{L}<\mathrm{S}, \mathrm{H}>\mathrm{S}\end{array}$ \\
\hline Depressive mood (MHI5 score $<66$ ) & $422(16)$ & $474(24)$ & $407(17)$ & $\mathrm{L}<\mathrm{H}, \mathrm{H}>\mathrm{S}$ \\
\hline \multicolumn{5}{|l|}{ Social support } \\
\hline Marginal emotional support (MOS-SSS score $<6$ ) & $251(10)$ & $197(10)$ & $205(8)$ & \\
\hline Marginal instrumental support & $424(16)$ & $370(19)$ & $230(10)$ & $\mathrm{L}>\mathrm{S}, \mathrm{H}>\mathrm{S}$ \\
\hline \multicolumn{5}{|l|}{ Social engagement } \\
\hline No group participation & $849(33)$ & $756(39)$ & $500(21)$ & $\mathrm{L}<\mathrm{H}, \mathrm{L}>\mathrm{S}, \mathrm{H}>\mathrm{S}$ \\
\hline
\end{tabular}

ulations (Table 2). Living alone status was in most cases more strongly associated with instrumental support [ORLondon $=6.3(95 \% \mathrm{CI} 4.8,8.1), \mathrm{OR}_{\mathrm{Hamburg}}=16.9(95 \% \mathrm{CI}$ $\left.11.1,25.7), \mathrm{OR}_{\text {Solothurn }}=4.7(95 \% \mathrm{CI} 3.3,6.7)\right]$, whereas risk for social isolation was more strongly related to marginal emotional support $\left[\mathrm{OR}_{\mathrm{London}}=7.7\right.$ (95\% CI 5.7, $10.5), \mathrm{OR}_{\text {Hamburg }}=6.7$ (95\% CI 4.7, 9.7), $\mathrm{OR}_{\text {Solothurn }}=5.9$ (95\% CI 4.0, 8.6)]. Living alone status showed no association with lack of social engagement, whereas risk of social isolation was moderately related to lack of social engagement $\left[\mathrm{OR}_{\text {London }}=2.2(95 \% \mathrm{CI} 1.7,2.8), \mathrm{OR}_{\mathrm{Ham}-}\right.$ burg $=2.6(95 \% \mathrm{CI} 2.0,3.4), \mathrm{OR}_{\text {Solothurn }}=4.6(95 \% \mathrm{CI}$ $3.4,6.3)]$. The results of the regression analyses of models including both social network measures (data not shown) were nearly identical to the individual models, indicating that LSNS-6 measures also significantly predict differences in social support and engagement, independent of the single-item living alone measure.

The adjusted associations for marginal family and friend network (Table 2) show a consistent pattern of stronger associations, dependent on the type of social network deficit with type of social support or social engagement. For example, subjects with a marginal social network were at least six times more likely across sites to have marginal emotional support with the deficit much more strongly related to having a marginal family network as opposed to having a marginal friend network. Marginal instrumental support was more closely related to the marginal family network and only moderately associated with the friend network. In contrast, subjects in all three sites with marginal friend network were over three times more likely to report no group participation.

\section{Non-responder analysis}

The non-respondent group ( $\mathrm{n}=1874)$ had slightly more women in all sites (London 61\% vs 54\%, Hamburg $73 \%$ us $63 \%$, Solothurn $59 \%$ vs $56 \%$; $p<0.05$ ), were slightly older in Hamburg 76.7 7.1 SD vs $74.0 \pm 6.4$ $\mathrm{SD}$ and Solothurn 75.3 $\pm 6.1 \mathrm{SD}$ vs $73.9 \pm 5.9 \mathrm{SD}$, $p<0.05)$, had a worse perception of their health in London (32\% fair/poor us 24\% and Solothurn 27\% fair/poor us $19 \%, p<0.05)$, but had no difference in hospital admissions during the preceding 12 months in comparison with responders $(n=6982)$.

\section{DISCUSSION}

Results from these analyses, fully adjusted for differences in measured characteristics, show that living alone 
Table 2 - Adjusted associations of social network measures with marginal emotional and instrumental support and social engagement in three European populations of community-dwelling older adults (total sample, $n=6982$ ).

\begin{tabular}{|c|c|c|c|}
\hline & $\begin{array}{c}\text { Marginal emotional } \\
\text { support } \\
\text { OR* }^{*}(95 \% \mathrm{CI})\end{array}$ & $\begin{array}{c}\text { Marginal instrumental } \\
\text { support } \\
\text { OR* }^{*}(95 \% \mathrm{CI})\end{array}$ & $\begin{array}{c}\text { Lack of social engagement } \\
\text { No group participation } \\
\text { OR* }^{*}(95 \% \text { CI })\end{array}$ \\
\hline $\begin{array}{l}\text { London }(\mathrm{n}=2598) \\
\text { Living alone } \\
\text { Risk for social isolation } \\
\text { Marginal family network } \\
\text { Marginal friend network }\end{array}$ & $\begin{array}{l}6.8(4.9,9.5) \\
7.7(5.7,10.5) \\
7.2(5.3,9.8) \\
4.1(3.0,5.5)\end{array}$ & $\begin{array}{l}6.3(4.8,8.1) \\
3.3(2.6,4.3) \\
3.9(3.0,5.0) \\
1.9(1.5,2.4)\end{array}$ & $\begin{array}{l}0.8(0.6,1.0) \\
2.2(1.7,2.8) \\
1.3(1.0,1.7) \\
3.0(2.4,3.7)\end{array}$ \\
\hline $\begin{array}{l}\text { Hamburg ( } \mathrm{n}=1964) \\
\text { Living alone } \\
\text { Risk for social isolation } \\
\text { Marginal family network } \\
\text { Marginal friend network }\end{array}$ & $\begin{array}{c}4.3(2.8,6.5) \\
6.7(4.7,9.7) \\
7.8(5.4,11.2) \\
3.6(2.5,5.2)\end{array}$ & $\begin{array}{c}16.9(11.1,25.7) \\
3.1(2.3,4.2) \\
3.6(2.6,4.9) \\
1.7(1.2,2.3)\end{array}$ & $\begin{array}{l}0.8(0.6,1.0) \\
2.6(2.0,3.4) \\
1.3(1.0,1.7) \\
3.6(2.8,4.6)\end{array}$ \\
\hline $\begin{array}{l}\text { Solothurn }(\mathrm{n}=2420) \\
\text { Living alone } \\
\text { Risk for social isolation } \\
\text { Marginal family network } \\
\text { Marginal friends network }\end{array}$ & $\begin{array}{l}2.1(1.4,3.1) \\
5.9(4.0,8.6) \\
6.3(4.2,9.6) \\
4.4(3.1,6.3)\end{array}$ & $\begin{array}{l}4.7(3.3,6.7) \\
3.4(2.3,5.1) \\
4.2(2.7,6.4) \\
2.3(1.6,3.2)\end{array}$ & $\begin{array}{l}1.2(0.9,1.6) \\
4.6(3.4,6.3) \\
3.7(2.6,5.3) \\
4.4(3.4,5.6)\end{array}$ \\
\hline
\end{tabular}

status and a brief measure of risk for social isolation perform differently across three European populations of community-dwelling older adults. The two measures demonstrated unique associations with measures of social support and social engagement, suggesting that each measure identifies a distinct group. The strong similar patterns of association across sites of the measure of risk of social isolation with social support and engagement demonstrate sensitivity to differences in social-structural and personal characteristics. This is essential to a better understanding of the proposed link between social network, social support, social engagement and health in older adults. Overall, these results emphasize the importance of expanding multidimensional geriatric assessment to include differentiated social network assessment.

Several limitations of this study should be considered. These findings are not generalizable to the general populations of community-dwelling older adults in each country. Due to the eligibility criteria of the PRO-AGE trial, older adults with dementia, terminal disease, or need for human assistance in the basic activities of daily living were excluded. In addition, social factors are closely related to cultural and regional factors, and therefore association patterns may be specific to the study population living in a defined geographical area within each site (31). Selection bias is also a potential threat to the validity of these study results, due to the high non-responder rate. However, the differences between responder and non-responder groups were small, supporting our conclusion that selection bias is unlikely to have influenced the validity of our findings. Another limitation is related to unmeasured factors such as income, another potentially important determinant of social factors and health in older people $(1$, 12, 27). For example, the European Union 2003 estimated at-risk-of-poverty rate in the UK and Germany was $24 \%$ and $15 \%$ respectively (32). This limitation is unlikely to have affected the results in Solothurn, due to the extremely low poverty rate among older persons in Switzerland (2006 poverty rate among Swiss older adults $<4 \%$ ) $(33,34)$. Lastly, as the study was based on cross-sectional data and temporality is unknown, the results only suggest mechanisms by which social network, demographic factors, health-related characteristics, social support, and social engagement are associated in populations of European older adults.

The present findings have research implications relevant for developing improved geriatric interventions targeted at improving the health and well-being of older adults. Given the diversity of social isolates, many types of intervention will be needed to address and strengthen social networks, and only by complete assessment of social network can interventions focused on mechanisms to bolster social ties be developed and tested. In general, future research is needed, involving a broad range of programs; ones designed to work with older adults, caregivers, family and friends to strengthen existing and create new social contacts, as well as interventions aimed at improving availability and/or access to counseling, social services and social programs. Future research into multidimensional geriatric assessment should also include differentiated measures of the social network, such as those used in this study. Such efforts will further our understanding of the nature of social networks and pathways 
to health, and guide future strategies for the prevention of social isolation and decline in older adults.

This study has clinical and public health implications. Multidimensional geriatric assessment, including living alone status, risk of social isolation, and lack of family and friendship ties can properly identify the population at risk of social deficits. The measures used in this research identify a relatively small proportion of communitydwelling older adults at risk of social isolation, and, with nominal added respondent burden, specifically inform about existing family and friendship resources. The specificity of social network assessment may be expected to add to the efficiency and efficacy of geriatric interventions by tailoring interventions to specific deficiencies in the social situations of individuals or groups of older adults.

\section{CONCLUSION}

Findings suggest that living alone status and a brief measure of social network identify distinct at-risk groups and potential pathways for intervention. Multidimensional geriatric assessment programs that are inclusive of a differentiated social network assessment may offer important knowledge regarding the centrality of social networks to the health and wellbeing of older adults. Such knowledge will enhance future geriatric research and clinical care, as well as public health initiatives for older adults.

\section{APPENDIX}

Individual items of a brief measure of risk for social isolation

1 . How many relatives or family members do you see or hear from at least once a month?

2. How many relatives or family members do you feel close to that you can call on them for help?

3. How many relatives or family members do you feel at ease with that you can talk about private matters?

4. How many friends/neighbors do you see or hear from at least once a month?

5. How many friends/neighbors do you feel close to that you can call on them for help?

6. How many friends/neighbors do you feel at ease with that you can talk about private matters?

Note: Measure based on the Lubben Social Network Scale (LSNS-6) (15)

\section{ACKNOWLEDGEMENTS}

The PRO-AGE project was supported by grants of the European Union (QLK6-CT-1999-02205), Federal Education and Science Ministry (Bern, Switzerland, BBW 990311.1), Swiss National Science Foundation (32-52804.97), Swiss Foundation for Health Promotion (Project No. 398) and Velux Foundation. The intervention programme in Hamburg was supported by the Bundesministerium für Familie, Senioren, Frauen und Jugend, the Max und Ingeburg Herz Foundation (group sessions), and the Robert Bosch Stiftung (preventive home visits). John C. Beck was supported with a grant from the Langley Research Institute, Pacific Palisades, CA, USA. Eva Blozik and Jan Wagner were supported with a "Forschungskolleg Geriatrie" Fellowship Grant from the Robert Bosch Foundation, Stuttgart, Germany. We thank the practitioners and participants involved in this study, who generously gave their time to ensure the success of this project. In addition, in Hamburg, thanks go to Ulrike Dapp for helping with conduct of the study, including sample recruitment, and Jennifer Anders for helping with data collection.
Conflict of interest and sponsor's role: This manuscript contains original material that has not been previously published. None of the authors have a conflict of interest. The sponsors had no role in the design, methods, subject recruitment, data collection, analysis, or manuscript preparation.

\section{REFERENCES}

1. Lubben J, Gironda M. Social support networks. In Osterweil D, Brummel-Smith K, Beck JC, eds. Comprehensive Geriatric Assessment. New York: McGraw Hill, 2000: 121-37.

2. Berkman LF, Glass T, Brissette I et al. From social integration to health: Durkheim in the new millennium. Soc Sci Med 2000; 51: 843-57.

3. Melchior M, Berkman LF, Niedhammer I et al. Social relations and self-reported health: a prospective analysis of the French Gazel cohort. Soc Sci Med 2003; 56: 1817-30.

4. Berkman L, Glass TA. Social integration, social networks, social supports and health. In Berkman LF, Glass TA, eds. Social Epidemiology. New York: Oxford Press, 2000: 137-73.

5. Bisschop MI, Kriegsman DM, van Tilburg TG et al. The influence of differing social ties on decline in physical functioning among older people with and without chronic diseases: the Longitudinal Aging Study Amsterdam. Aging Clin Exp Res 2003; 15: 164-73.

6. Psychological and social issues, American Geriatrics Society (New York, NY), 2005. (http://www.healthinaging.org/ agingintheknow/chapters_ch_trial.asp?ch=3\#Social\%20involveme nt).

7. Keller BK, Magnuson TM, Cernin PA et al. The significance of social network in a geriatric assessment population. Aging Clin Exp Res 2003; 15: 512-7.

8. Guilley E, Pin S, Spini D et al. Association between social relationships and survival of Swiss octogenarians. A five-year prospective, population-based study. Aging Clin Exp Res 2005; 17 : 419-25.

9. Iliffe S, Kharicha K, Harari D et al. Health risk appraisal in older people 2: the implications for clinicians and commissioners of social isolation risk in older people. Br J Gen Pract 2007; 57: 27782.

10. Kharicha K, Iliffe S, Harari D et al. Health risk appraisal in older people 1: are older people living alone an "at-risk" group? Br J Gen Pract 2007; 57: 271-6.

11. Seeman TE. Social ties and health: the benefits of social integration. Ann Epidemiol 1996; 6: 442-51.

12. Stuck AE, Walthert JM, Nikolaus T et al. Risk factors for functional status decline in community-living elderly people: a systematic literature review. Soc Sci Med 1999; 48: 445-69.

13. Ferrucci L, Guralnik JM, Studenski S et al. Designing randomized, controlled trials aimed at preventing or delaying functional decline and disability in frail, older persons: a consensus report. J Am Geriatr Soc 2004; 52: 625-34.

14. Rubenstein LZ, Shekelle P, Tucker J et al. Health risk appraisals and Medicare. Baltimore: U.S. Department of Health and Human Services, Health Care Financing Administration, 2003.

15. Lubben J, Blozik E, Gillmann G et al. Performance of an abbreviated version of the Lubben Social Network Scale among three European community-dwelling older adult populations. Gerontologist 2006; 46: 503-13.

16. Ell K. Social networks, social support and coping with serious illness: the family connection. Soc Sci Med 1996; 42: 173-83.

17. Stuck AE, Kharicha K, Dapp U et al. The PRO-AGE study: an international randomised controlled study of health risk appraisal for older persons based in general practice. BMC Med Res Methodol 2007; 7: 2. 
18. Stuck AE, Elkuch P, Dapp U et al. Feasibility and yield of a selfadministered questionnaire for health risk appraisal in older people in three European countries. Age Ageing 2002; 31: 463-7.

19. Stuck AE, Kharicha K, Dapp U et al. Development, feasibility and performance of a health risk appraisal questionnaire for older persons. BMC Med Res Methodol 2007; 7: 1.

20. Lubben JE. Assessing social networks among elderly populations. Fam Community Health 1988; 11: 42-52.

21. Lawton MP, Brody EM. Assessment of older people: self-maintaining and instrumental activities of daily living. Gerontologist 1969; 9: 179-86.

22. Breslow L, Beck JC, Morgenstern H et al. Development of a health risk appraisal for the elderly (HRA-E). Am J Health Promot 1997; 11: 337-43.

23. Stewart AL, Hays RD, Ware JE Jr. The MOS short-form general health survey. Reliability and validity in a patient population. Med Care 1988; 26: 724-35.

24. Friedman B, Heisel M, Delavan R. Validity of the SF-36 five-item Mental Health Index for major depression in functionally impaired, community-dwelling elderly patients. J Am Geriatr Soc 2005; 53: 1978-85.

25. Sherbourne CD, Stewart AL. The MOS social support survey. Soc Sci Med 1991; 32: 705-14.

26. Boult C, Dowd B, McCaffrey D et al. Screening elders for risk of hospital admission. J Am Geriatr Soc 1993; 41: 811-7.

27. Lubben J, Gironda M. Centrality of social ties to the health and well-being of older adults. In Berkman B, Harootyan U, eds. Social Work and Health Care in an Aging Society: Education, Practice, and Research. New York: Springer, 2003: 319-50.

28. Zunzunegui MV, Alvarado BE, Del Ser T et al. Social networks, social integration, and social engagement determine cognitive decline in community-dwelling Spanish older adults. J Gerontol B Psychol Sci Soc Sci 2003; 58: S93-100.

29. Kirkwood BR, Sterne JAC. Essential Medical Statistics. Blackwell Publishing, 1988.

30. Greenland S. Chapter 21: introduction to regression modeling. In Rothman KG, Greenland S, eds. Modern Epidemiology. Philadelphia, PA: Lippincott-Raven, 1998: 401-34.

31. Seeman TE, Berkman LF, Kohout $F$ et al. Intercommunity variations in the association between social ties and mortality in the elderly. A comparative analysis of three communities. Ann Epidemiol 1993; 3: 325-35.

32. Zaidi A. Poverty of elderly people EU25. Vienna: European Centre for Social Welfare Policy and Research, 2006.

33. Schoenenberger AW, Stuck AE. Health care for older persons in Switzerland: a country profile. J Am Geriatr Soc 2006; 54: 986-90.

34. Personen ohne primäres soziales Netzwerk nach soziodemografischen Merkmalen 2003: Übersichtstabelle zum Herunterladen. Swiss Federal Statistical Office, 2006.

35. Hsu JC. Multiple Comparisons: Theory and Methods. London, UK: Chapman \& Hall, 1996. 